\title{
Crystallinity Improvement of ZnO Thin Film on Different Buffer Layers Grown by MBE
}

\author{
Shao-Ying Ting, ${ }^{1}$ Po-Ju Chen, ${ }^{2,3}$ Hsiang-Chen Wang, ${ }^{2,3}$ Che-Hao Liao, ${ }^{1}$ Wen-Ming Chang, \\ Ya-Ping Hsieh, ${ }^{2,3}$ and C. C. Yang ${ }^{1}$ \\ ${ }^{1}$ Institute of Photonics and Optoelectronics, National Taiwan University, Taipei 10617, Taiwan \\ ${ }^{2}$ Graduate Institute of Opto-Mechatronics, National Chung Cheng University, Chia-Yi 62102, Taiwan \\ ${ }^{3}$ Advanced Institute for Manufacturing with High-Tech Innovations, National Chung Cheng University, Chia-Yi 62102, Taiwan
}

Correspondence should be addressed to Hsiang-Chen Wang, hcwang@ccu.edu.tw

Received 23 November 2011; Revised 1 February 2012; Accepted 2 February 2012

Academic Editor: J. C. Sczancoski

Copyright (c) 2012 Shao-Ying Ting et al. This is an open access article distributed under the Creative Commons Attribution License, which permits unrestricted use, distribution, and reproduction in any medium, provided the original work is properly cited.

\begin{abstract}
The material and optical properties of $\mathrm{ZnO}$ thin film samples grown on different buffer layers on sapphire substrates through a two-step temperature variation growth by molecular beam epitaxy were investigated. The thin buffer layer between the $\mathrm{ZnO}$ layer and the sapphire substrate decreased the lattice mismatch to achieve higher quality ZnO thin film growth. A GaN buffer layer slightly increased the quality of the $\mathrm{ZnO}$ thin film, but the threading dislocations still stretched along the $c$-axis of the GaN layer. The use of $\mathrm{MgO}$ as the buffer layer decreased the surface roughness of the $\mathrm{ZnO}$ thin film by $58.8 \%$ due to the suppression of surface cracks through strain transfer of the sample. From deep level emission and rocking curve measurements it was found that the threading dislocations play a more important role than oxygen vacancies for high-quality $\mathrm{ZnO}$ thin film growth.
\end{abstract}

\section{Introduction}

Recently, $\mathrm{ZnO}$ has received considerable attention due to its excellent emission properties in the UV region. $\mathrm{ZnO}$ is a direct band-gap material with wurtzite-structure, exhibits a wide band-gap of $3.37 \mathrm{eV}$, and has a large exciton binding energy of $60 \mathrm{meV}$ at room temperature [1]. Based on these fundamental properties, $\mathrm{ZnO}$ has many applications in the short wavelength region such as optically pumped lasers, UV light emitting diodes, detectors, solar cells, and gas sensors [2-6]. However, the growth of $\mathrm{ZnO}$ thin film for such applications still remains problematic. So far, various methods have been employed to grow high quality $\mathrm{ZnO}$ thin films, for example, sputtering, pulsed laser deposition, metal organic chemical vapor deposition (MOCVD), and molecular beam epitaxy (MBE) [7-10]. MBE is a promising technique for the growth of high quality $\mathrm{ZnO}$ thin films due to its operation in ultra-high-vacuum conditions $\left(>10^{-9}\right.$ torr), using ultra pure substrates $(6 \mathrm{~N})$, and Angstrom-scale-thickness control. $\mathrm{ZnO}$ films are grown on different substrates including c$\mathrm{Al}_{2} \mathrm{O}_{3}, \mathrm{ZnO}, \mathrm{GaN}$, and $\mathrm{ScAlMgO}_{4}$. Among these substrates, c- $\mathrm{Al}_{2} \mathrm{O}_{3}$ is the most frequently used because of its low price, ease of producing large wafers, and ready availability for growing epitaxial films [11]. When $\mathrm{ZnO}$ films are grown on $\mathrm{c}-\mathrm{Al}_{2} \mathrm{O}_{3}$ substrates without a buffer layer, however, the $\mathrm{ZnO}$ films generally show poor crystalline quality with a high dislocation density because of the $18 \%$ lattice mismatch between $\mathrm{ZnO}$ and $\mathrm{c}-\mathrm{Al}_{2} \mathrm{O}_{3}$. Furthermore, a large difference in the thermal expansion coefficients between $\mathrm{ZnO}$ and $\mathrm{c}$ $\mathrm{Al}_{2} \mathrm{O}_{3}\left(\alpha_{\mathrm{ZnO}}=6.51 \times 10^{-6} \mathrm{~K}^{-1}\right.$ and $\alpha_{\text {sapphire }}=8.00 \times$ $10^{-6} \mathrm{~K}^{-1}$ ) will generate strain under the high temperature growth conditions. Chen et al. demonstrated a two-step growth method that carries out the initial growth at a lower temperature followed by a growth step at high temperature. Through this method a densely packed $\mathrm{ZnO}$ film with larger grains and well-aligned crystallographic orientation can be obtained [12].

In addition, the improvement in growth quality by using a buffer layer to decrease the lattice mismatch between $\mathrm{ZnO}$ and $\mathrm{c}-\mathrm{Al}_{2} \mathrm{O}_{3}$ is a well-known method. These thin buffer layers for growing $\mathrm{ZnO}$ are $\mathrm{GaN}, \mathrm{MgO}, \mathrm{ZnS}$, or $\mathrm{SiC}$ [1316]. GaN and $\mathrm{MgO}$ are the most popular buffer layers for 
ZnO grown on sapphire substrate. With the GaN buffer layer, the similar lattice structure, low lattice mismatch between $\mathrm{ZnO}$ and $\mathrm{GaN}$, and similar thermal expansion coefficients $\left(\alpha_{\mathrm{GaN}}=5.59 \times 10^{-6} \mathrm{~K}^{-1}\right)$ provide suitable conditions for $\mathrm{ZnO}$ growth [17]. Thus, a GaN buffer layer can solve the cracking problem during the quick growth of $\mathrm{ZnO}$ thin films by acting as a homoepitaxy quasi substrate [18]. A ZnO thin film on a GaN buffer layer on a c-sapphire substrate does, however, suffer compressive stress.

When using $\mathrm{MgO}$ as a buffer layer there are two approaches to solving the issues of high quality $\mathrm{ZnO}$ growth. For high temperature growths $\left(750-850^{\circ} \mathrm{C}\right)$, the interaction between $\mathrm{MgO}$ and $\mathrm{Al}_{2} \mathrm{O}_{3}$ dominats: the $\mathrm{Mg}^{2+}$ and $\mathrm{Al}^{3+}$ diffuse to form a spinel intermediate layer $\left(\mathrm{MgAl}_{2} \mathrm{O}_{4}\right)$. The $18 \%$ lattice mismatch between $\mathrm{ZnO}$ and $\mathrm{Al}_{2} \mathrm{O}_{3}$ is stepwise divided between $\mathrm{ZnO} / \mathrm{MgO}, \mathrm{MgO} /$ spinel, and spinel $/ \mathrm{Al}_{2} \mathrm{O}_{3}$. A maximum mismatch of about $9.2 \%$ remains at the $\mathrm{ZnO} / \mathrm{MgO}$ interface while the lattice mismatch between the $\mathrm{MgO}$ grains and the spinel layer is about 5.6\%. Experiments reveal that the density of threading dislocation decreases by a factor of five when using $\mathrm{MgO}$ as the buffer layer [19].

For $\mathrm{ZnO}$ growth at low temperature $\left(\sim 600^{\circ} \mathrm{C}\right)$, the reaction between $\mathrm{MgO}$ and $\mathrm{Al}_{2} \mathrm{O}_{3}$ cannot occur, but the $\mathrm{MgO}$ buffer layer still decreases the lattice mismatch during the $\mathrm{ZnO}$ growth. For thin $\mathrm{MgO}$ layers, the $\mathrm{ZnO}$ grown on the $\mathrm{MgO}$ layer is a layer-by-layer epitaxy and the threading dislocations cannot stretch along the $c$-axis of the $\mathrm{ZnO}$. In such a condition, the threading dislocations of the $\mathrm{ZnO}$ cluster occur only within $20 \mathrm{~nm}$ of the $\mathrm{ZnO} / \mathrm{MgO}$ interface, which can improve the crystallization quality of the $\mathrm{ZnO}$ growth [20, 21].

In this paper, the growth of $\mathrm{ZnO}$ thin films on $c$-plane sapphire substrates by a two-step temperature variation was demonstrated using different MBE-deposited buffer layers. Temperature-dependent photoluminescence results showed the optical features of $\mathrm{ZnO}$ thin film samples with and without buffer layers. The crystallization quality and strain distribution of $\mathrm{ZnO}$ structures were analyzed through X-ray diffraction (XRD) and X-ray rocking curve (XRC) measurements. The surface morphologies of the $\mathrm{ZnO}$ thin films were studied by atomic force microscopy (AFM) and scanning electron microscopy (SEM). The $\mathrm{ZnO}$ thin film with a $7 \mathrm{~nm}$ thick $\mathrm{MgO}$ buffer layer, $18 \mathrm{~nm}$ thick low-temperature-grown $\mathrm{ZnO}$ layer, and $100 \mathrm{~nm}$ thick high-temperature-grown $\mathrm{ZnO}$ layer showed the best crystallization properties in this study.

\section{Growth Conditions and Structures of the Growth Samples}

The $\mathrm{ZnO}$ thin films were grown on commercial (0001) c$\mathrm{Al}_{2} \mathrm{O}_{3}$ substrates by $\mathrm{MBE}$. For Sample $\mathrm{A}, \mathrm{ZnO}$ was grown with a thickness of $6 \mathrm{~nm}$ at low temperature (LT) on the c- $\mathrm{Al}_{2} \mathrm{O}_{3}$ substrate with no buffer layer. In this step, the growth temperature, beam equivalent pressure, and $\mathrm{O}_{2}$ flow rate were $500^{\circ} \mathrm{C}, 5 \times 10^{-7}$ torr, and $3 \mathrm{sccm}$, respectively. Then $\mathrm{ZnO}$ was grown with a thickness of $600 \mathrm{~nm}$ at high temperature (HT) on the LT-ZnO layer. In this step, the growth temperature, beam equivalent pressure, and $\mathrm{O}_{2}$ flow rate were $600^{\circ} \mathrm{C}, 6 \times 10^{-7}$ torr, and $4 \mathrm{sccm}$, respectively. Sample B is a $\mathrm{ZnO}$ thin film on a GaN buffer layer. The GaN buffer layer was grown on a $\mathrm{c}-\mathrm{Al}_{2} \mathrm{O}_{3}$ substrate at $1,000^{\circ} \mathrm{C}$ with a thickness of $2 \mu \mathrm{m}$ by MOCVD. Then the LT-ZnO was grown with a thickness of $10 \mathrm{~nm}$ on the GaN buffer layer. In this step, the growth temperature, beam equivalent pressure, and $\mathrm{O}_{2}$ flow rate were $300^{\circ} \mathrm{C}, 5 \times 10^{-7}$ torr, and $3 \mathrm{sccm}$, respectively. Finally, HT- $\mathrm{ZnO}$ was grown with a thickness of $250 \mathrm{~nm}$ on the LT-ZnO layer. In this step, the growth temperature, beam equivalent pressure, and $\mathrm{O}_{2}$ flow rate were $600^{\circ} \mathrm{C}, 5 \times 10^{-7}$ torr, and $2 \mathrm{sccm}$, respectively. Samples $\mathrm{C}, \mathrm{D}$, and $\mathrm{E}$ were $\mathrm{ZnO}$ thin films on $7 \mathrm{~nm}$ thick $\mathrm{MgO}$ buffer layers, which were grown on $\mathrm{c}-\mathrm{Al}_{2} \mathrm{O}_{3}$ substrates. In this step, the growth temperature, beam equivalent pressure, and $\mathrm{O}_{2}$ flow rate were $550^{\circ} \mathrm{C}, 2 \times 10^{-7}$ torr, and $3 \mathrm{sccm}$, respectively. For these samples, the growth conditions of the LT-ZnO layers were the same as for Sample B. But sample D had an $18 \mathrm{~nm}$-thick LT-ZnO layer. For the HT-ZnO layers, these three samples had the same growth temperature of $600^{\circ} \mathrm{C}$ as for Sample B. In this step, the growth thickness, beam equivalent pressure, and $\mathrm{O}_{2}$ flow rate of Samples $\mathrm{C}, \mathrm{D}$, and E were $400 \mathrm{~nm}, 7.5 \times 10^{-7}$ torr, and $3.5 \mathrm{sccm} ; 100 \mathrm{~nm}, 5.0 \times$ $10^{-7}$ torr, and $2.5 \mathrm{sccm} ; 100 \mathrm{~nm}, 5.0 \times 10^{-7}$ torr, and $1.4 \mathrm{sccm}$, respectively. Figure 1 summarizes the layer structures of the samples.

Samples A, B, C, and D were grown in an $\mathrm{O}_{2}$-rich condition. Sample $\mathrm{E}$ was grown in the stoichiometric condition $\left(\mathrm{Zn}: \mathrm{O}_{2}=1: 1\right)$, which results in more oxygen vacancies. After the HT-ZnO layers' growth, all of the samples were annealed at $700^{\circ} \mathrm{C}$ for 10 minutes to improve crystallization. Table 1 shows the growth parameters of the samples.

\section{XRD and XRCs Measurements}

Figure 2 shows the XRD spectra of the samples with only (002) $\mathrm{ZnO}$ peak. Figure 3 shows the normalized XRC results of the samples. In this figure, the largest full width at half maximum (FWHM) of 791.74 arcsec was measured in Sample A, which indicated that a high density of threading dislocations existed due to a larger lattice mismatch between $\mathrm{ZnO}$ and $\mathrm{c}-\mathrm{Al}_{2} \mathrm{O}_{3}$. The FWHM of Sample B was 242.58 arcsec, a $69.40 \%$ decrease from sample A. This decrease came from the small lattice mismatch of $1.80 \%$ between $\mathrm{ZnO}$ and $\mathrm{GaN}$, which resulted in a decrease of the dislocation density in the $\mathrm{ZnO}$ layer. However, many threading dislocations still existed in the GaN buffer layer due to the larger lattice mismatch of $16 \%$ between $\mathrm{GaN}$ and the $\mathrm{c}-\mathrm{Al}_{2} \mathrm{O}_{3}$ substrate. In this study, the GaN buffer layer in Sample B was thicker than MgO buffer layers in Samples C, D, and E to minimize the influence of lattice mismatch between $\mathrm{GaN}$ and $\mathrm{c}-\mathrm{Al}_{2} \mathrm{O}_{3}$ for high quality $\mathrm{ZnO}$ thin film growth [13]. Thus, the GaN buffer layer showed some limitations for high quality $\mathrm{ZnO}$ thin film growth. The FWHM of Samples C, D, and E are 64.18, 48.66, and 98.01 arcsec, respectively, representing $91.89 \%, 93.85 \%$, and $87.60 \%$ decreases compared to Sample A. These results indicate the higher quality of $\mathrm{ZnO}$ growth on an $\mathrm{MgO}$ buffer layer. Although the lattice mismatch between $\mathrm{MgO}$ and $\mathrm{ZnO}$ of $8.4 \%$ is more than that between $\mathrm{ZnO}$ and $\mathrm{GaN}(1.8 \%)$, 


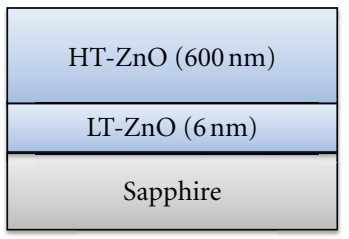

Sample A

(a)

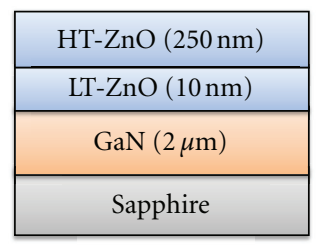

Sample B (b)

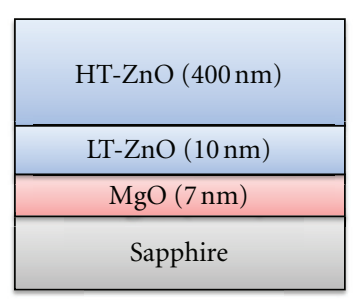

Sample C

(c)

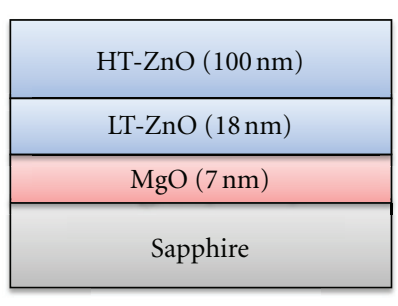

Sample D

(d)

\begin{tabular}{|c|}
\hline $\mathrm{HT}-\mathrm{ZnO}(100 \mathrm{~nm})$ \\
\hline $\mathrm{LT}-\mathrm{ZnO}(10 \mathrm{~nm})$ \\
\hline $\mathrm{MgO}(7 \mathrm{~nm})$ \\
\hline Sapphire \\
\hline
\end{tabular}

Sample E

(e)

Figure 1: Schematic picture for the layer structures of (a) Sample A, (b) Sample B, (c) Sample C, (d) Sample D, and (e) Sample E used in this work.

TABLE 1: The growth parameters of $\mathrm{ZnO}$ thin film samples.

\begin{tabular}{|c|c|c|c|c|c|}
\hline sample & HT-ZnO growth temperature $\left({ }^{\circ} \mathrm{C}\right)$ & HT-ZnO growth conditions & HT-ZnO thickness (nm) & $\mathrm{LT}-\mathrm{ZnO}$ & Buffer layer \\
\hline A & 600 & $\mathrm{O}_{2}$-rich & 600 & $500^{\circ} \mathrm{C} 6 \mathrm{~nm}$ & $\mathrm{~N} / \mathrm{A}$ \\
\hline B & 600 & $\mathrm{O}_{2}$-rich & 250 & $300^{\circ} \mathrm{C} 10 \mathrm{~nm}$ & $1000^{\circ} \mathrm{C} 2 \mu \mathrm{m} \mathrm{GaN}$ \\
\hline $\mathrm{C}$ & 600 & $\mathrm{O}_{2}$-rich & 400 & $300^{\circ} \mathrm{C} 10 \mathrm{~nm}$ & $550^{\circ} \mathrm{C} 7 \mathrm{~nm} \mathrm{MgO}$ \\
\hline $\mathrm{D}$ & 600 & $\mathrm{O}_{2}$-rich & 100 & $300^{\circ} \mathrm{C} 18 \mathrm{~nm}$ & $550^{\circ} \mathrm{C} 7 \mathrm{~nm} \mathrm{MgO}$ \\
\hline $\mathrm{E}$ & 600 & $\mathrm{Zn}: \mathrm{O}_{2}=1: 1$ & 100 & $300^{\circ} \mathrm{C} 10 \mathrm{~nm}$ & $550^{\circ} \mathrm{C} 7 \mathrm{~nm} \mathrm{MgO}$ \\
\hline
\end{tabular}

the $\mathrm{MgO}$ buffer can effectively suppress the stretching of threading dislocations to the $c$-axis of the $\mathrm{ZnO}$ layer. The highest degree of crystallinity was achieved for $\mathrm{ZnO}$ thin films grown on $7 \mathrm{~nm}$ thick $\mathrm{MgO}$ buffer layers, which is a fivefold improvement over the $2 \mu \mathrm{m}$ thick GaN buffer layer.

Table 2 shows the material parameters of $\mathrm{ZnO}$ thin film samples obtained from XRD measurement. The grain size of each sample was calculated using the Sherrer equation [2225]: $D=0.94 \lambda / \beta \cos \theta$. Here $D, \lambda, \beta$, and $\theta$ are the grain size, beam wavelength $(0.15405 \mathrm{~nm})$, FWHM, and diffraction angle of the XRD measurement, respectively. In Table 2, the lattice parameters $a$ and $c$ were calculated through the Bragg Diffraction equation $(2 d \sin \theta=n \lambda)$ and the lattice equation of the wurtzite structure (1) [22]:

$$
\begin{gathered}
a=d_{h k l} \sqrt{\frac{4}{3}\left(h^{2}+h k+k^{2}\right)+l^{2}\left(\frac{a}{c}\right)^{2}}, \\
\frac{a}{c}=\sqrt{\frac{8}{3}} .
\end{gathered}
$$

Here $d_{h k l}$ is the interplanar distance and $h, k, l$ are the Miller Indices. The biaxial stress was calculated by comparing the c-lattice constant to the strain-free lattice parameter $(c$ $0=0.5205 \mathrm{~nm}$ ) measured from a $\mathrm{ZnO}$ powder sample: $\sigma$

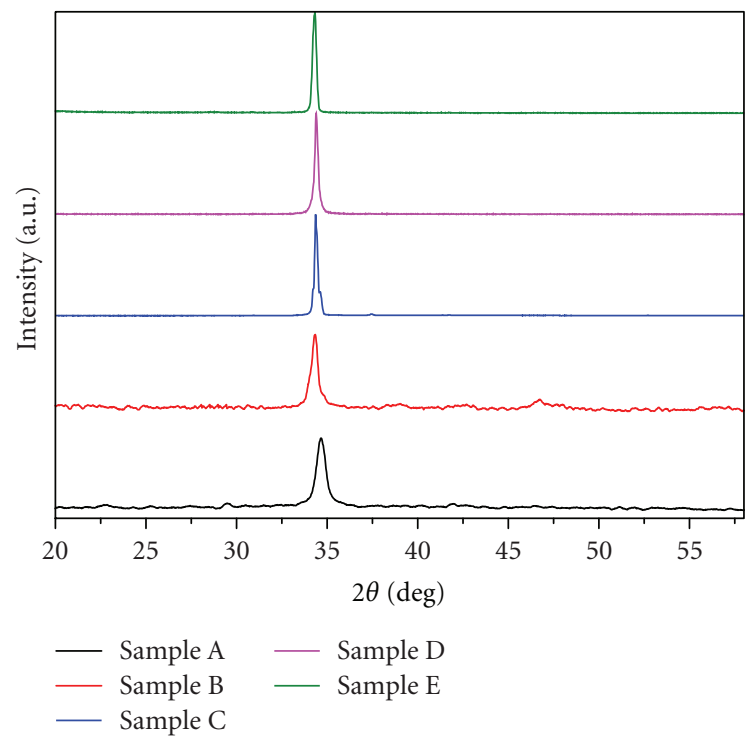

Figure 2: XRD $\omega-2 \theta$ spectra of the Samples A, B, C, D, and E.

$=-453.6 \times 10^{9}\left[\left(c-c_{0}\right) / c_{0}\right]$. The strain was calculated by: $\varepsilon=\beta / 4 \tan \theta[22-24,26]$. 
TABle 2: Peak position, FWHM, grain size, strain, stress, and lattice constants $(d)$ of the samples from XRD measurements and derived lattice parameters $(a, c)$.

\begin{tabular}{|c|c|c|c|c|c|c|c|c|}
\hline Sample & 2 theta (degree) & FWHM (acrsec) & Grain size $(\mathrm{nm})$ & Strain (microstrain) & Stress (Gpa) & $d(\AA)$ & $a(\AA)$ & $c(\AA)$ \\
\hline A & 34.68 & 791.74 & 37.872 & 299.624 & 3.306 & 2.584 & 3.164 & 5.167 \\
\hline B & 34.33 & 242.58 & 123.493 & 90.809 & -1.171 & 2.609 & 3.196 & 5.218 \\
\hline C & 34.37 & 64.18 & 466.849 & 24.057 & -0.606 & 2.606 & 3.192 & 5.212 \\
\hline $\mathrm{D}$ & 34.41 & 48.66 & 615.805 & 18.261 & -0.120 & 2.603 & 3.188 & 5.206 \\
\hline $\mathrm{E}$ & 34.33 & 98.01 & 305.715 & 36.692 & -1.145 & 2.609 & 3.195 & 5.218 \\
\hline
\end{tabular}

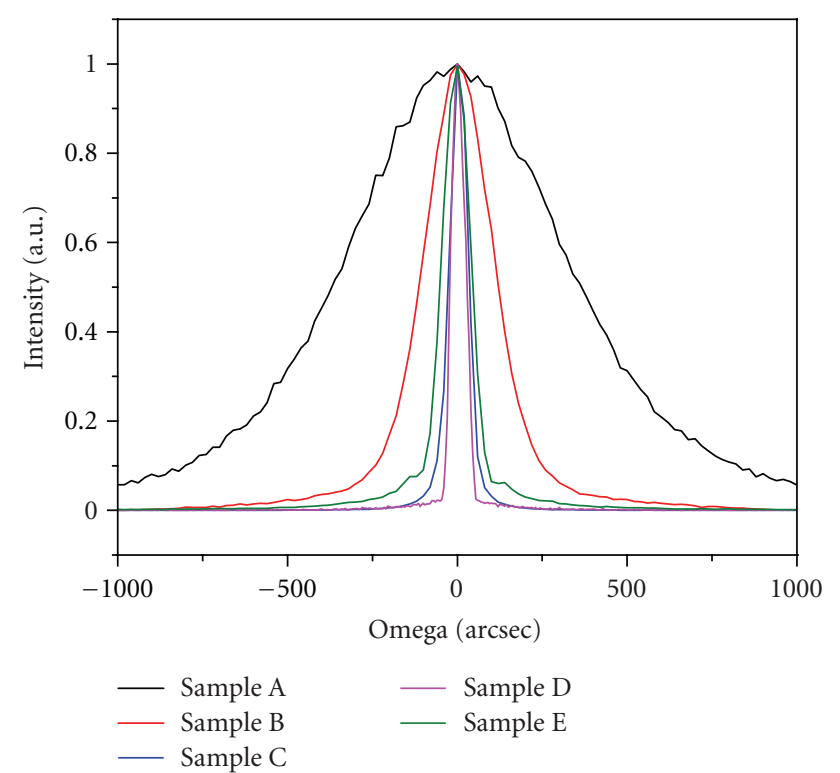

Figure 3: Normalized XRC results of the Samples A, B, C, D, and E.

From these calculations the $\mathrm{ZnO}$ layer in Sample A suffered tensile stress of $3.306 \mathrm{GPa}$ and 299.624 microstrain. The high tensile stress caused cracking during the $\mathrm{ZnO}$ thin film growth. In Sample B, the $\mathrm{ZnO}$ layer suffered compressive stress of $-1.171 \mathrm{GPa}$ and 90.809 microstrain. The change from tensile stress to compressive stress using $\mathrm{GaN}$ as a buffer layer can solve the problem of the film cracking.

Using $\mathrm{MgO}$ as a buffer layer (Samples $\mathrm{C}, \mathrm{D}$, and $\mathrm{E}$ ) resulted in an increased strain release in the $\mathrm{ZnO}$ thin film growth. In sample $\mathrm{D}$, the minimum compressive stress $(-0.120 \mathrm{GPa})$ and strain $(18.261$ microstrain $)$ were observed and were found to be close to the stress-free condition. These results imply that threading dislocations were effectively confined in the $\mathrm{ZnO} / \mathrm{MgO}$ interface due to the cubic structure of $\mathrm{MgO}$ during the $\mathrm{ZnO}$ thin film growth [20, 21]. Sample D exhibited the highest crystalline quality $\mathrm{ZnO}$ thin film in this study.

\section{Deep Level and Edge Band Emission}

The PL spectra of the $\mathrm{ZnO}$ thin film samples at room temperature (Figure 4(a)) show strong edge band emissions (EBE) with very weak deep level emissions (DLE), which confirms their good crystalline and optical quality. The bandedge emission peaks of the samples are located at $3.312 \mathrm{eV}$, $3.305 \mathrm{eV}, 3.304 \mathrm{eV}, 3.298 \mathrm{eV}$, and $3.317 \mathrm{eV}$, for Samples A, $\mathrm{B}, \mathrm{C}, \mathrm{D}$, and $\mathrm{E}$, respectively, while the broad DLE peaks are at about $2.25 \mathrm{eV}$. The DLE results reveal the presence of defects and oxygen vacancies in the $\mathrm{ZnO}$ thin films [25]. In order to compare the optical quality of these samples, the integrated intensity ratio of the EBE to the DLE as a function of temperature for each of the samples is shown in Figure 4(b). The integrated intensity of EBE and DLE ranges from $2.918 \mathrm{eV}$ to $3.758 \mathrm{eV}$ and $1.771 \mathrm{eV}$ to $2.756 \mathrm{eV}$, respectively, corresponding to the shaded areas in Figure 4(a). The EBE/DLE values decrease rapidly with increasing temperature up to some specific temperature for each of the samples. These specific temperatures are approximately $45 \mathrm{~K}, 45 \mathrm{~K}, 75 \mathrm{~K}, 90 \mathrm{~K}$, and $75 \mathrm{~K}$ for Samples $\mathrm{A}, \mathrm{B}, \mathrm{C}, \mathrm{D}$, and $\mathrm{E}$, respectively. Above these specific temperatures, no rapid decrease in EBE/DLE values is observed. The specific temperature represents the critical temperature below which radiative recombination dominates and above which nonradiative recombination dominates. For Sample A the low EBE/DLE values in all temperature ranges represent a higher density of threading dislocations, more stress, and higher defect density in the $\mathrm{ZnO}$ thin film, corresponding to the lower optical quality of the sample. The EBE/DLE values increase significantly in the samples with $\mathrm{GaN}$ or $\mathrm{MgO}$ buffer layers. These results confirm the improvement of $\mathrm{ZnO}$ thin film crystallinity from using $\mathrm{GaN}$ and $\mathrm{MgO}$ buffer layers. When comparing Sample E to Samples C and $\mathrm{D}$, the apparently lower optical quality of Sample E originates from the stoichiometric growth condition $\left(\mathrm{Zn}: \mathrm{O}_{2}=1: 1\right)$. This growth condition induces more oxygen vacancies in the $\mathrm{ZnO}$ layer leading to a higher DLE intensity. This order of DLE intensity for the samples is the same for the entire temperature range.

In order to check the consistency between the optical measurements and structural measurements, the integrated intensity ratio of the EBE to the DLE and the inverse FWHM of the XRC of each samples are shown in Figure 5. The maximum EBE/DLE means the EBE/DLE value of sample at $10 \mathrm{~K}$. Higher EBE/DLE ratios and higher values for $\mathrm{FWHM}^{-1}$ from XRC measurements represent improved optical and material qualities of the samples. Samples C, D, and E, with $\mathrm{MgO}$ buffer layers, show an enhancement of their crystalline and optical qualities. Sample B with a GaN buffer layer exhibits inferior results. Sample A without any buffer layer had the worst quality. 


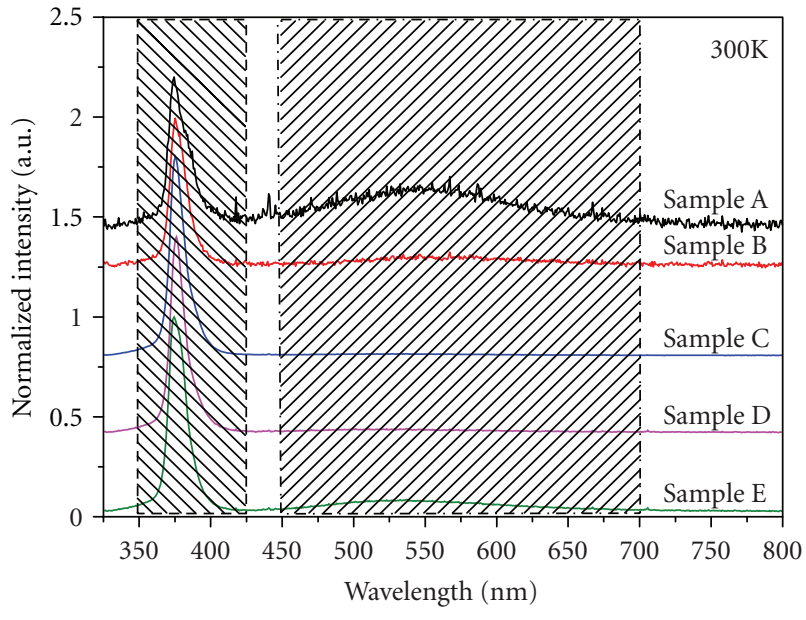

(a)

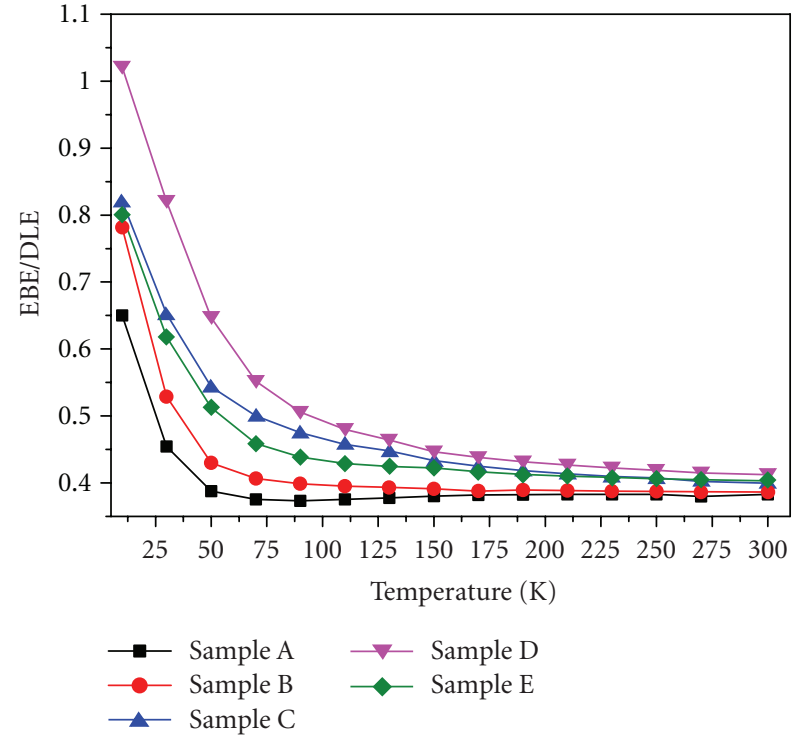

(b)

Figure 4: (a) Photoluminescence and deep level emission spectra of the Samples A, B, C, D, and E at room temperature, (b) the integrated intensity ratio of the EBE to the DLE of samples as functions of temperature.

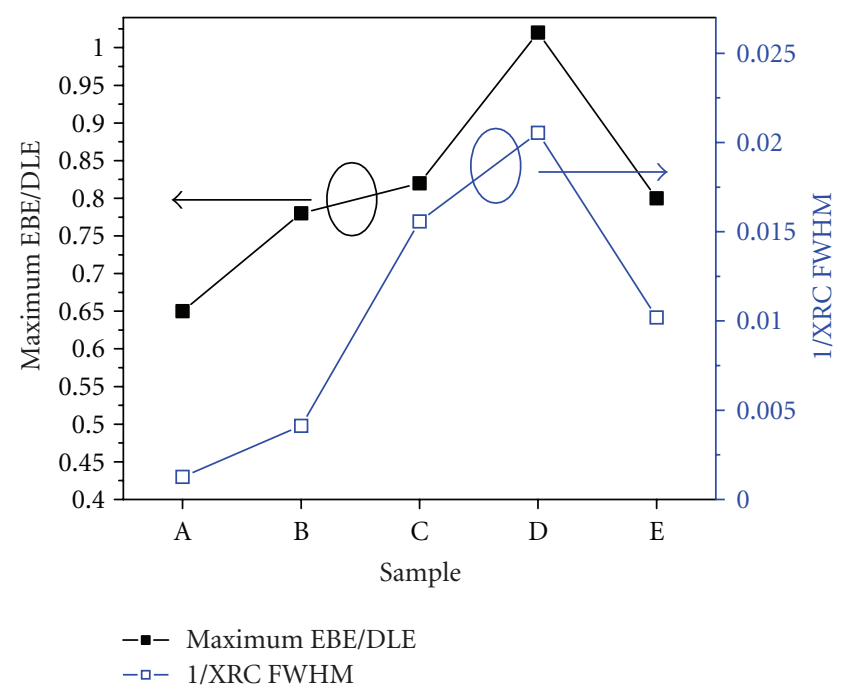

FIGURE 5: The integrated intensity ratio of the EBE to the DLE and the inverse FWHM of XRC of Samples A, B, C, D, and E.

\section{SEM and AFM Images}

Figures 6(a) and 6(b) show SEM and AFM images of Samples $A$ and D. In the SEM image of Sample A (Figure 6(a)), surface pits can be seen. The rougher surface of Sample A compared to Sample D originates from the larger lattice mismatch in the $\mathrm{ZnO} /$ sapphire interface. The large tensile stress in Sample A is induced by this increased lattice mismatch. AFM measurement reveals a larger root mean square (RMS) roughness of about $6.982 \mathrm{~nm}$ without a buffer layer. For the $\mathrm{MgO}$ buffer layer in sample $\mathrm{D}$, the RMS roughness is about $2.875 \mathrm{~nm}$. The decrease in RMS roughness by $58.8 \%$ is attributed to the change from tensile stress to compressive stress when using the MgO buffer layer compared to no buffer layer. These results indicate that the growth of $\mathrm{ZnO}$ thin films on buffer layers, especially $\mathrm{MgO}$, results in better crystallinity of samples, thus improved optical characteristics.

In summary, by including a buffer layer in the growth of $\mathrm{ZnO}$ thin films, the lattice mismatch of the film surface to the sapphire substrate surface was decreased significantly. Including a GaN buffer layer in Sample B resulted in higher optical and structural quality than Sample A. The comparison between $\mathrm{ZnO}$ growth on the $\mathrm{GaN}$ and the $\mathrm{MgO}$ buffer layers shows that dislocations stretching along the $c$-axis could not be suppressed effectively by a thick GaN buffer layer. Samples C, D, and E were of higher quality than sample B.

For the $\mathrm{MgO}$ buffer layer growth, the stoichiometric growth condition induced more oxygen vacancies in the $\mathrm{ZnO}$ layer, resulting in lower crystal quality in Sample E compared to Samples C and D. In the two-step temperature variation growth, the optimal LT-ZnO thickness was about $40 \mathrm{~nm}$ for Sample D [11], which showed the highest crystallinity in this study. Thus, the LT-ZnO has an important effect in changing the crystal quality of the following HT-ZnO. The LT-ZnO with optimal thickness could cause relatively disordered $\mathrm{HT}-\mathrm{ZnO}$ growth on the $\mathrm{MgO}$ buffer layer resulting in a three-dimensional island morphology, resulting in different defect configurations in the HT-ZnO layer [11]. From the description above, one can see that the order of $\mathrm{ZnO}$ thin film crystallinity, from best to worst, is D, C, E, B, and A.

\section{Conclusion}

In conclusion, the influence of the $\mathrm{GaN}$ and $\mathrm{MgO}$ buffer layers on the structural, electrical, and optical properties 


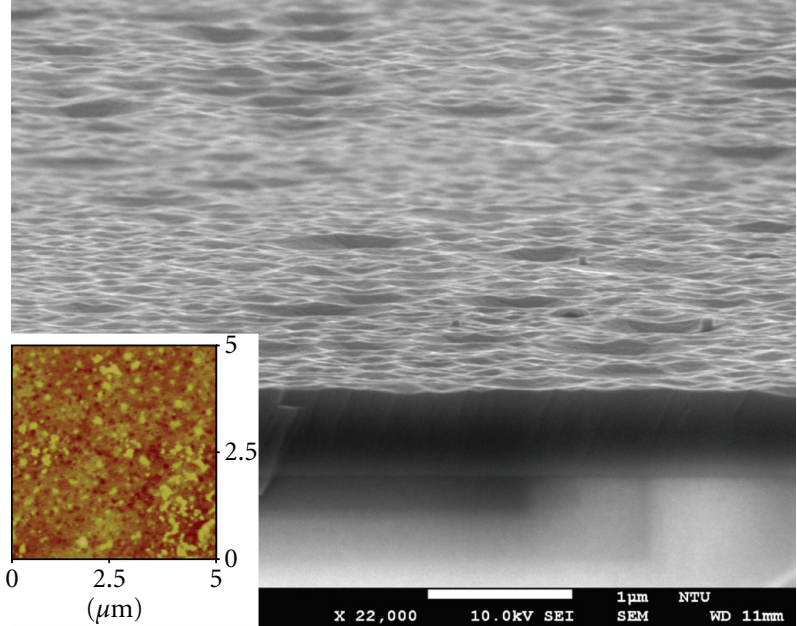

(a)

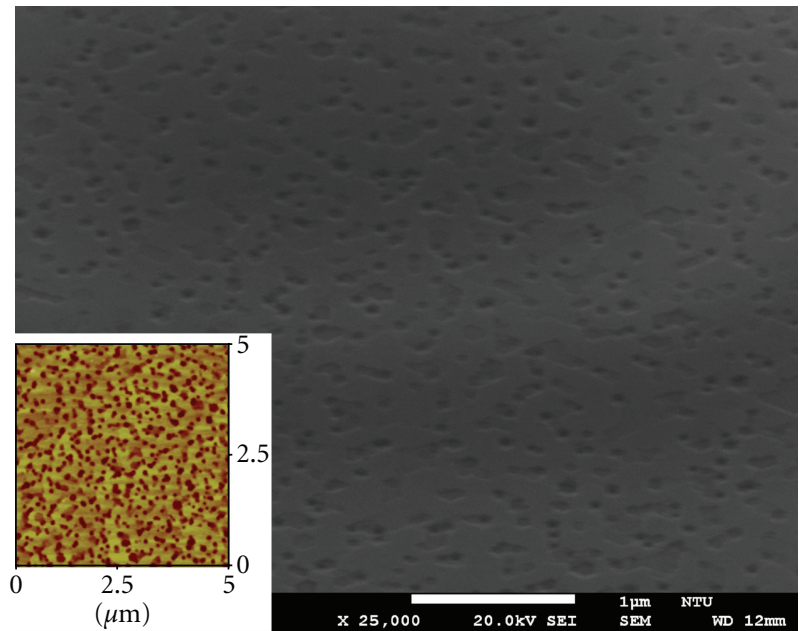

(b)

Figure 6: SEM and AFM images of (a) Sample A and (b) Sample D.

of $\mathrm{ZnO}$ thin films grown on sapphire substrates by $\mathrm{MBE}$ was investigated. The XRD and XRCs investigations revealed that the buffer layer had diminished the strain and changed the stress from tensile to compressive, leading to threading dislocation elimination. The PL revealed a strong edge band emission with a weak deep level emission, suggesting the good crystalline quality of the $\mathrm{ZnO}$ thin films on the $\mathrm{MgO}$ buffer layer. The increase in the integrated intensity ratio of the EBE to the DLE and the inverse FWHM of XRC with GaN and $\mathrm{MgO}$ as buffer layers demonstrated the enhancement of the structural and optical qualities of the $\mathrm{ZnO}$ thin films.

\section{Acknowledgments}

This research was supported by National Science Council, China, under the Grants of NSC 99-2221-E-002-123-MY3, 100-2622-E-002-008-CC2, 100-2221-E-002-170，100-2221E-194-043, by NTU Excellent Research Project (10R80908B), and by US Air Force Scientific Research Office under the contract of AOARD-11-4114.

\section{References}

[1] D. C. Look, "Recent advances in $\mathrm{ZnO}$ materials and devices," Materials Science and Engineering B, vol. 80, no. 1-3, pp. 383387, 2001.

[2] D. M. Bagnall, Y. F. Chen, Z. Zhu et al., "Optically pumped lasing of $\mathrm{ZnO}$ at room temperature," Applied Physics Letters, vol. 70, no. 17, pp. 2230-2232, 1997.

[3] J. H. Lim, C. K. Kong, K. K. Kim, I. K. Park, D. K. Hwang, and S. J. Park, "UV electroluminescence emission from $\mathrm{ZnO}$ lightemitting diodes grown by high-temperature radiofrequency sputtering," Advanced Materials, vol. 18, no. 20, pp. 27202724, 2006.

[4] S. Liang, H. Sheng, Y. Liu, Z. Huo, Y. Lu, and H. Shen, "ZnO Schottky ultraviolet photodetectors," Journal of Crystal Growth, vol. 225, no. 2-4, pp. 110-113, 2001.
[5] M. Law, L. E. Greene, J. C. Johnson, R. Saykally, and P. Yang, "Nanowire dye-sensitized solar cells," Nature Materials, vol. 4, no. 6, pp. 455-459, 2005.

[6] Q. Wan, Q. H. Li, Y. J. Chen et al., "Fabrication and ethanol sensing characteristics of $\mathrm{ZnO}$ nanowire gas sensors," Applied Physics Letters, vol. 84, no. 18, pp. 3654-3656, 2004.

[7] Y. Zhang, G. Du, D. Liu et al., "Crystal growth of undoped $\mathrm{ZnO}$ films on Si substrates under different sputtering conditions," Journal of Crystal Growth, vol. 243, no. 3-4, pp. 439443, 2002.

[8] S. K. Hong, H. J. Ko, Y. Chen, and T. Yao, "Control of $\mathrm{ZnO}$ film polarity," Journal of Vacuum Science and Technology B, vol. 20, no. 4, pp. 1656-1663, 2002.

[9] T. Gruber, C. Kirchner, K. Thonke, R. Sauer, and A. Waag, "MOCVD growth of $\mathrm{ZnO}$ for optoelectronic applications," Physica Status Solidi A, vol. 192, no. 1, pp. 166-170, 2002.

[10] M. Fujita, N. Kawamoto, T. Tatsumi, K. Yamagishi, and Y. Horikoshi, "Molecular beam epitaxial growth of $\mathrm{ZnO}$ on $\mathrm{Si}$ substrate using ozone as an oxygen source," Japanese Journal of Applied Physics Part 1, vol. 42, no. 1, pp. 67-70, 2003.

[11] J. G. Kim, S. K. Han, S. M. Yang et al., "Effects of low temperature $\mathrm{ZnO}$ and $\mathrm{MgO}$ buffer thicknesses on properties of $\mathrm{ZnO}$ films grown on (0001) $\mathrm{Al} 2 \mathrm{O} 3$ substrates by plasmaassisted molecular beam epitaxy," Thin Solid Films, vol. 519, no. 1, pp. 223-227, 2010.

[12] Y. J. Chen, Y. Y. Shih, C. H. Ho, J. H. Du, and Y. P. Fu, "Effect of temperature on lateral growth of $\mathrm{ZnO}$ grains grown by MOCVD," Ceramics International, vol. 36, no. 1, pp. 69-73, 2010.

[13] X. Q. Wang, H. P. Sun, and X. Q. Pan, "Effect of GaN interlayer on polarity control of epitaxial $\mathrm{ZnO}$ thin films grown by molecular beam epitaxy," Applied Physics Letters, vol. 97, no. 15, Article ID 151908, 2010.

[14] B. Pecz, A. El-Shaer, A. Bakin, A. C. Mofor, A. Waag, and J. Stoemenos, "Structural characterization of $\mathrm{ZnO}$ films grown by molecular beam epitaxy on sapphire with MgO buffer," Journal of Applied Physics, vol. 100, no. 10, Article ID 103506, 2006. 
[15] A. A. Ashrafi, A. Ueta, H. Kumano, and I. Suemune, "Role of $\mathrm{ZnS}$ buffer layers in growth of zincblende $\mathrm{ZnO}$ on $\mathrm{GaAs}$ substrates by metalorganic molecular-beam epitaxy," Journal of Crystal Growth, vol. 221, no. 1-4, pp. 435-439, 2000.

[16] Z. D. Sha, J. Wang, Z. C. Chen et al., "Initial study on the structure and optical properties of $\mathrm{ZnO}$ film on $\mathrm{Si}\left(\begin{array}{lll}1 & 1 & 1\end{array}\right)$ substrate with a SiC buffer layer," Physica E, vol. 33, no. 1, pp. 263-267, 2006.

[17] B. M. Ataev, W. V. Lundin, V. Mamedov, A. M. Bagamadova, and E. E. Zavarin, "Low-pressure chemical vapour deposition growth of high-quality $\mathrm{ZnO}$ films on epi-GaN/ $\alpha-\mathrm{Al} 2 \mathrm{O} 3$," Journal of Physics Condensed Matter, vol. 13, no. 9, pp. L211L214, 2001.

[18] J. P. Cui, Y. Duan, X. F. Wang, and Y. P. Zeng, "Strain status in $\mathrm{ZnO}$ film on sapphire substrate with a GaN buffer layer grown by metal-source vapor phase epitaxy," Microelectronics Journal, vol. 39, no. 12, pp. 1542-1544, 2008.

[19] A. Bakin, J. Kioseoglou, B. Pecz et al., "Misfit reduction by a spinel layer formed during the epitaxial growth of $\mathrm{ZnO}$ on sapphire using a $\mathrm{MgO}$ buffer layer," Journal of Crystal Growth, vol. 308, no. 2, pp. 314-320, 2007.

[20] Y. Chen, H. J. Ko, S. K. Hong, and T. Yao, "Layer-by-layer growth of $\mathrm{ZnO}$ epilayer on $\mathrm{Al} 2 \mathrm{O} 3(0001)$ by using a $\mathrm{MgO}$ buffer layer," Applied Physics Letters, vol. 76, no. 5, pp. 559$561,2000$.

[21] Y. Chen, S. K. Hong, H. J. Ko et al., "Effects of an extremely thin buffer on heteroepitaxy with large lattice mismatch," Applied Physics Letters, vol. 78, no. 21, pp. 3352-3354, 2001.

[22] P. Singh, A. Kumar, Deepak, and D. Kaur, "ZnO nanocrystalline powder synthesized by ultrasonic mist-chemical vapour deposition," Optical Materials, vol. 30, no. 8, pp. 1316-1322, 2008.

[23] W. Taeg Lim and C. Hyo Lee, "Highly oriented $\mathrm{ZnO}$ thin films deposited on Ru/Si substrates," Thin Solid Films, vol. 353, no. 1, pp. 12-15, 1999.

[24] J. Ye, S. Gu, S. Zhu et al., "The growth and annealing of single crystalline $\mathrm{ZnO}$ films by low-pressure MOCVD," Journal of Crystal Growth, vol. 243, no. 1, pp. 151-156, 2002.

[25] B. H. Kong, D. C. Kim, S. K. Mohanta, and H. K. Cho, "Influence of VI/II ratios on the growth of $\mathrm{ZnO}$ thin films on sapphire substrates by low temperature MOCVD," Thin Solid Films, vol. 518, no. 11, pp. 2975-2979, 2010.

[26] D. Sahu, B. S. Acharya, and A. K. Panda, "Role of Ag ions on the structural evolution of nano $\mathrm{ZnO}$ clusters synthesized through ultrasonication and their optical properties," Ultrasonics Sonochemistry, vol. 18, no. 2, pp. 601-607, 2011. 

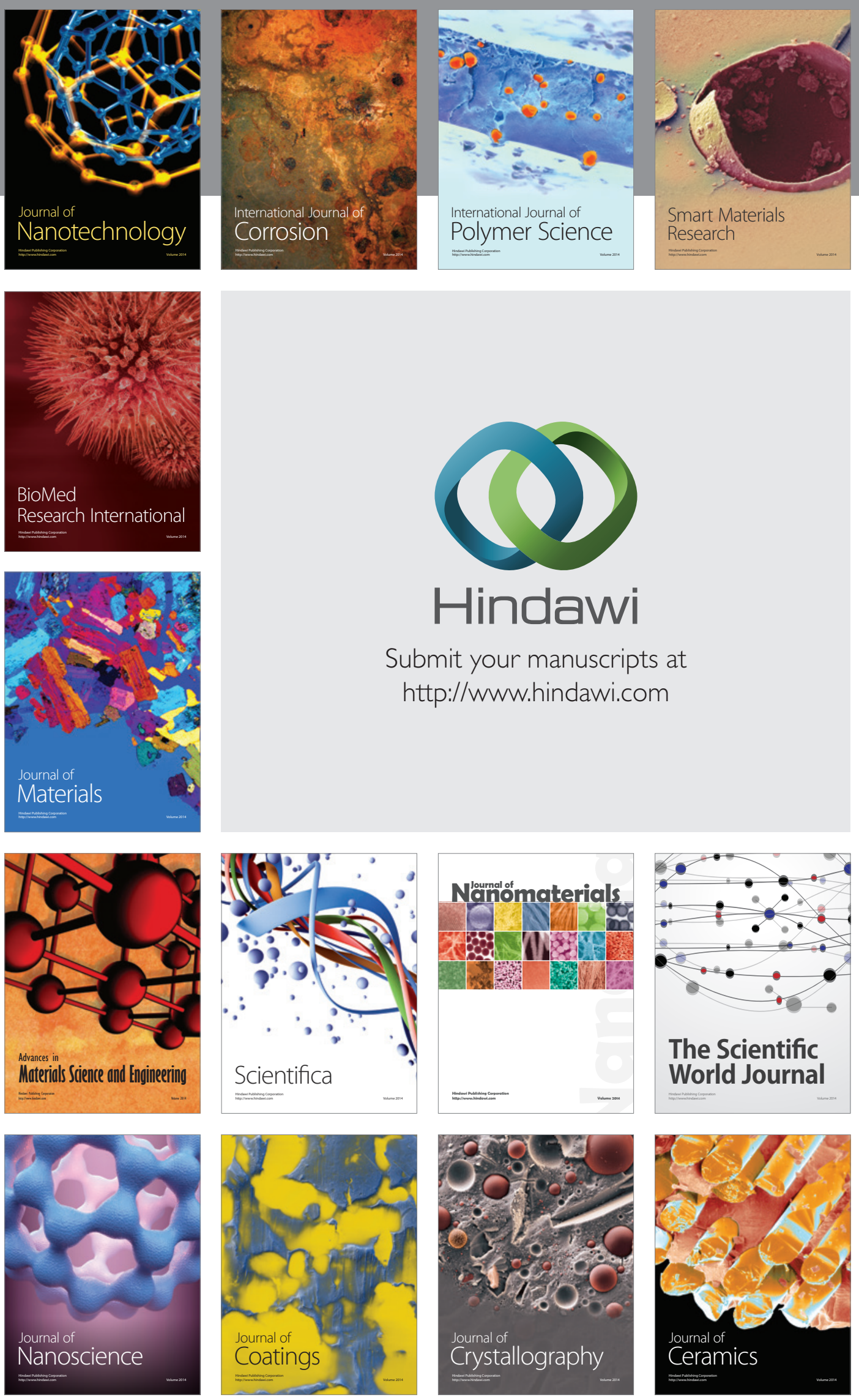

The Scientific World Journal

Submit your manuscripts at

http://www.hindawi.com

\section{World Journal}

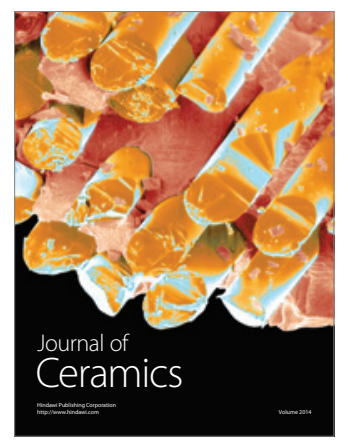

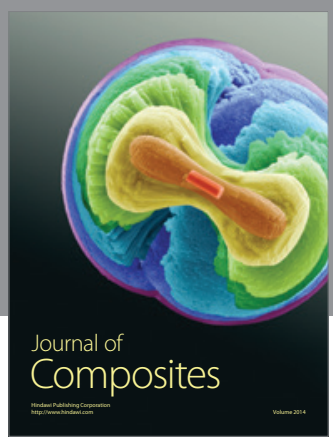
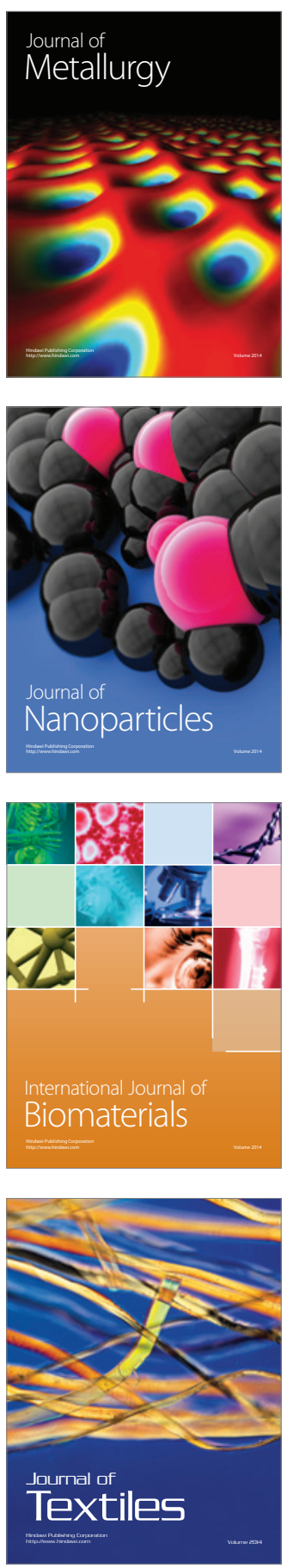